\title{
Is pertussis actually reemerging? Insights from an individual-based model
}

\author{
A coqueluche realmente está reermegindo? \\ Reflexões a partir de um modelo baseado \\ no indivíduo
}

Cláudia Torres Codeço 1

Paula Mendes Luz 1

\footnotetext{
1 Programa de Computação Científica, Fundação

Oswaldo Cruz.

Av. Brasil 4365,

Rio de Janeiro, $R J$ 21045-900, Brazil. codeco@procc.fiocruz.br pluz@procc.fiocruz.br
}

\begin{abstract}
In this paper, we introduce a spatially explicit, individual-based model developed to simulate the dynamics of pertussis in a small population. With this simulation approach, complex epidemic systems can be built using information on parasite population structure (strain diversity, virulence diversity, etc.), human population structure (individual risk, age structure, interaction matrices, immune response, etc.), as well as mechanisms of evolution and learning. We parameterized our model to describe pertussis in an age-structured community. Pertussis or whooping cough is an acute infection of the respiratory tract caused by Bordetella pertussis. Despite wide-scale vaccination in many countries, this disease is reemerging throughout the world in both adults and children. Emergence has been explained by many factors: wane of vaccine and natural immunity, increase of asymptomatic carriers, and/or natural selection of non-vaccine strains. Here, we model these hypotheses and analyze their potential impact on the observed increase of pertussis notification.
\end{abstract}

Key words Whooping Cough; Pertussis Vaccine; Computer Simulation

Resumo Neste trabalho, nós apresentamos um modelo de indivíduos, cuja representação espacial é explícita, para simular a dinâmica da coqueluche numa pequena população. Utilizando esta abordagem de simulação, podemos construir modelos complexos utilizando informações sobre a estrutura populacional dos parasitas (diversidade fenotípica, de virulência, etc) sobre a estrutura populacional humana (risco individual, estrutura etária, matrizes de interação, resposta imunológica, etc) assim como processos evolutivos e de aprendizagem. Nós parametrizamos este modelo para representar a dinâmica da coqueluche numa população com estrutura etária. Coqueluche é uma infecção aguda do trato respiratório, causada por Bordetella pertussis. Apesar da vacinação em larga escala em vários países, esta infecção está reemergindo por todo o mundo, atacando adultos e crianças. Reemergência tem sido atribuída a vários fatores: perda gradual da imunidade adquirida; aumento do número de portadores assintomáticos; seleção natural de variantes resistentes à vacina. Aqui, nós modelamos estas hipóteses e analisamos seu potencial explicativo com relação ao aumento de casos de coqueluche.

Palavras-chave Coqueluche; Vacina de Coqueluche; Simulação por Computador 


\section{Introduction}

In recent years there has been a trend towards more complex models in epidemiology. This tendency is in part due to the increasing computational power available that allows us to run more detailed models. It is also in part due to the increasing awareness of the role of individual heterogeneity on disease dynamics. Complexity is introduced in epidemiological models in many ways. For example, hierarchical models incorporate individual - as well as population-level factors as determinants of the dynamics of transmission (Goldstein, 1995). Structured models include details on human population structure as variations of risk, immunity, antibody production, transmission probability, etc. (Engen, 1992).

Here, we present a spatially explicit, individual-based model for the simulation of human-parasite dynamics. Some major traits distinguish individual-based models from traditional population-based models (for an introduction to the latter, see Anderson \& May, 1991). In individual-based models, processes and mechanisms are modeled in the form of rules rather than mathematical functions (Wiegand, 1998). These rules describe the actions and behaviors that each individual should perform in response to changes in the environment and in itself. The advantage of this approach is that we can include biological information in the model that is not necessarily based on hard data, for example, human behavior, patterns of interaction, etc. (for an introduction to individual-based models, see DeAngelis \& Gross, 1992). Rules are static if they are fixed (aging rules for example). Dynamic rules, on the other hand, may change over the course of an individual's lifetime (learning) or between generations (evolution). For example, immune response and human behavior are dynamic rules that change as individuals learn new strategies to avoid infection. In the same way, rules governing parasitic attack may change as parasites evolve new strategies.

Individual-based models have been successfully applied to the modeling of ecological communities (Grimm, 1999; Uchmanski et al., 1999) and microbiological populations (Kreft et al., 1998). In an epidemiological context, they are becoming increasingly common. Some examples in epidemiology are found in Holmes (1997), Ferguson et al. (1997), and Rhodes \& Anderson (1996). We believe that this approach can provide important insights in the study of evolution and dynamics of infectious diseases.
In this paper, we model pertussis epidemiology using an individual-based model. Pertussis or whopping cough is an acute infection of the respiratory tract caused by Bordetella pertussis. Despite wide-scale vaccination in many countries, this disease is reemerging throughout the world in both adults and children (CDC, 1993a, 1993b, 1997). Emergence has been explained by many factors: wane of vaccine and natural immunity, increase of asymptomatic carriers, and/or natural selection of non-vaccine strains. Here, we model these hypotheses and analyze their potential impact on the observed increase of notification.

\section{Pertussis: clinical and epidemiological aspects}

Pertussis is an infection transmitted by respiratory droplets. The incubation period averages from 9 to 14 days. Onset is insidious, and the first symptoms resemble a minor infection of the upper respiratory tract. Symptoms last about 6 weeks and can be divided into 3 categories: catarrhal stage (with cough, coryza, lacrimation, anorexia, and malaise), paroxysmal stage (with bursts of rapid, consecutive coughs followed by a deep, high-pitched inspiration), and convalescent stage (in which a decrease occurs in the frequency and severity of cough paroxysms). Most of these symptoms are usually present in children, but asymptomatic cases are also observed. Minor and major complications (epistaxis secondary to paroxysms and pneumonia, encephalopathy), including death (case-fatality rate $0.6 \%$ in the 1980 s, Plotkin \& Orenstein, 1999), may occur, especially in infants under one year old (Gangarosa et al., 1998). All infants should receive pertussis vaccine associated with diphtheria and tetanus toxoids (DPT), in a total of 6 doses, at ages 2, 4, and 6 months, 15-18 months, and a booster dose at 4 to 6 years of age (Fauci et al., 1998).

Recently, pertussis has been observed with increasing frequency in highly vaccinated populations: in the Netherlands, whose vaccination coverage exceeds $95 \%$, and in the United States, with a coverage of ca. $85 \%$ (de Melker et al., 2000; Hethcote, 1999). In Brazil, incidence of bacteriologically-confirmed cases has decreased since the 1980 s, when ca. $75 \%$ of children ages 1-4 years were protected with 3 doses of DPT. However, in 1997, there was an increase in the number of cases reported (DATASUS), despite ca. $80 \%$ of vaccination coverage (da Silva et al., 1999). Most reported cases were preschool children. More recently, however, a 
significant increase among older children, adolescents, and adults has been observed (Plotkin \& Orenstein, 1999; Wright, 1995). The majority of these individuals had been vaccinated or infected by Bordetella pertussis in the past. Contrary to what was previously thought, immunity acquired by vaccine or infection is not lifelong (Plotkin \& Orenstein, 1999; Van Loo, 1999; Veronesi \& Focaccia, 1996), and individuals become susceptible again after approximately 12 years. Because these re-infections are generally asymptomatic or because they are not diagnosed as pertussis, cases are only reported in the presence of an outbreak. Usually, infected adults (which act as a reservoir for the infection) carry the bacteria into their households and transmit it to younger children (Veronesi \& Focaccia, 1996). The latter suffer the most from the disease, which often progresses to complications (Fauci et al., 1998).

Many hypotheses have been proposed to explain the observed increase in pertussis notification (CDC, 1996; de Melker et al., 2000; Plotkin \& Orenstein, 1999; Veronesi \& Focaccia, 1996): (1) decrease in DPT vaccine efficacy; (2) decrease in vaccination coverage; (3) increasing notification rate; (4) reduction of natural boosting due to high vaccination coverage; and (5) antigenic shift of circulating pertussis strain (Van Loo, 1999).

According to de Melker et al. (2000) and Hethcote (1999) there is no evidence to support the first two hypotheses, at least in the United States and the Netherlands. In these countries, vaccine quality complies with high standards and vaccination coverage is actually increasing. A search for the explanation has concentrated on the last three hypotheses. Hethcote $(1997,1999)$ defends hypothesis 3 in his analysis of pertussis in United States. He built an age-structured mathematical model for pertussis and parameterized it to represent American demographic (age population structure) and epidemiological features (vaccination coverage and force of infection). His model suggests that the current increase in notified cases in the United States may not represent true epidemics, but merely a change in the notification rate. Van Boven et al. (2000) adapted a modified version of Hethcote's model (1997) to data from the Netherlands. Their model points to hypothesis 5 as the most probable factor explaining the pertussis outbreak observed in their notification dataset. These authors discard the possibility of increasing medical awareness.

Here, we study a simulated population infected with pertussis. The goal is to predict the effect of hypotheses 3 to 5 on key epidemiolog- ical parameters. If sufficient differences are found, we can use these parameters as indicators of the most probable cause. The advantage of using a simulated community is that we have access to the "true" infection dynamics. This in contrast with previous modeling work whose parameterization is based on notification data. Pertussis notification represents less than $10 \%$ of the actual prevalence in the United States (Hethcote, 1999; Marchant, 1994) and probably less than that in other countries (Miller, 2000). Besides, notification is strongly biased towards lower age classes (CDC, 1996).

In the next section, we introduce our model and describe the implementation of each simulated scenario.

\section{Model Structure}

We used an individual-based model to create a pertussis-infected community. This modeling approach allows us to explicitly represent each individual in population, as well as their spatial coordinates (Lomnick, 1999). Our simulated community consists of 2,500 individuals living on a 2-dimensional world. This world is a 100x100 grid with 10,000 sites where each site fits at most one individual. Individuals are randomly distributed throughout the world. Host age distribution is flat, i.e., the population is evenly distributed throughout all ages. This seems to be a reasonable assumption for developed countries (Anderson \& May, 1991). To generate a flat distribution, we assumed that people can only die at the maximum age of 720 months (ca. 60 years). For each person that dies of old age, a newborn is created and randomly allocated on the map. The balance between births and deaths maintains a stable population density and age structure.

Each simulation step corresponds to a month in the individual's life. The month-tomonth routine of individuals in the simulated community is given by a set of rules. At each simulation step, each individual moves to a new site in its neighborhood (simulating a local movement) and ages 1 month (Figure 1).

At time zero, we introduce an infected person into the community. During 2 time steps (the infectious period), this person transmits the infection to susceptible individuals within its contact distance. Contact distance is defined by a $3 \times 3$ square centered on an individual's position (Figure 1). This rule seems reasonable considering that transmission of pertussis to households occurs with a chance of 90-100\% (Edwards et al, 1999) and gives an in- 
Figure 1

Model diagram
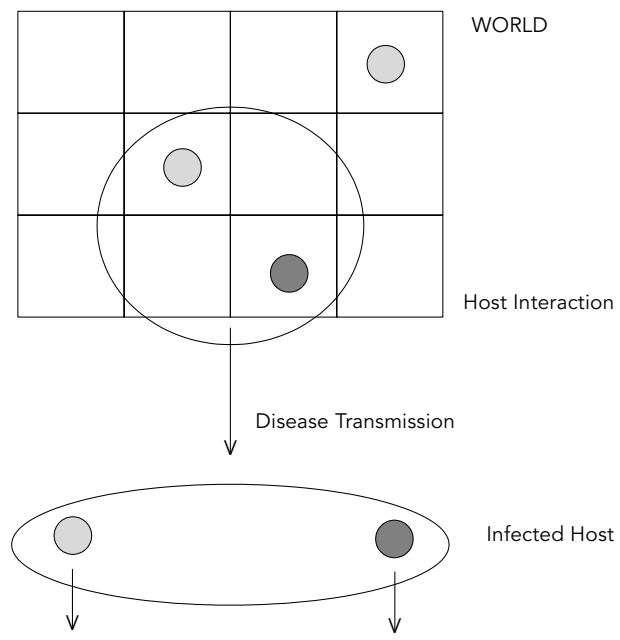

Move and Age

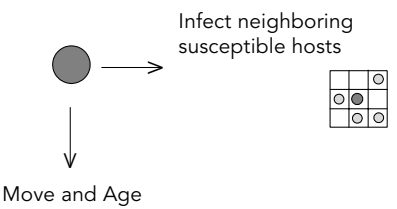

fection reproduction rate $\left(\mathrm{R}_{0}\right)$ of ca. 10 (expected for pertussis, according to Anderson \& May, 1991). Newly infected individuals remain infectious for 2 time steps, during which they transmit the infection to others within their contact distance. The continuation of this dynamic results in an infection wave running throughout the world. For simplicity, we assume that nobody dies of pertussis. Therefore, after 2 simulation steps, each individual recovers and becomes immune. We also assume that age does not affect host susceptibility or infection transmissibility.

Studies suggest that pertussis infection does not confer lifelong immunity, although some controversy still exists about its duration (Mahon et al., 2000). Most authors agree that pertussis immunity is highest right after vaccination or infection (ca. 90\%). Twelve years later, however, immunity is already only $10 \%$ (Edwards et al., 1999). We model immunity decay as a half-normal curve (Figure 2):

$$
i(t)=i(0) e^{\left(-w^{2} t^{2}\right)}
$$

where $i(t)$ is the individual's current degree of immunity (ranging from 0 to 1 ); $i(0)$ is the maximum degree of immunity provided by the infection or vaccination $(i(0)=1) ; w$ is the monthly rate of immunity decay; and $t$ is the period since last contact with the pertussis antigen (either by infection or vaccination).

Full immunity (due to recent host contact with pathogen or vaccine) confers $100 \%$ protection against infection. As immunity starts to wane, chances of getting a new infection increase. Let us consider a person who caught pertussis 5 years ago. According to equation (1), his/her degree of immunity is now 0.6. If the person enters into contact with the infectious agent today, he/she has a $60 \%$ chance of not becoming infectious (the person may be infected but not infectious). This contact with the agent boosts his/her immunity again to the maximum (100\%) (Hethcote, 1999).

Since there is still some controversy about the duration of pertussis immunity, we opted for simulating two basic situations (Table 1). The first assumes that pertussis immunity is lifelong $(w=0)$. The second assumes that immunity wanes with time ( $w=0.012$; Figure 3$)$.

All simulations are initialized without vaccination. Since this is a stochastic model with a small population size, pertussis eventually goes extinct after the number of susceptibles decrease below a threshold (Anderson \& May, 1991). To restore the dynamics, a new pathogen must be introduced into the community. This is carried out by periodically seeding a random person in the community with the infectious agent, simulating the arrival of an infected individual (Rhodes \& Anderson, 1996).

The non-vaccinated pertussis model is run for 2,400 time steps, corresponding to 200 years. This long run ensures that steady-state is reached. A number of epidemiological parameters are collected: outbreak duration, total number of infected individuals per outbreak, age distribution, and outbreak maximum prevalence. After 200 years, we introduce vaccination. For simplicity, we assume that infants are vaccinated at 6 months and 1.5 years, becoming fully protected against the disease. We assume that vaccine-induced immunity has the same duration pattern of naturally acquired immunity.

Vaccination is implemented with $95 \%$ coverage. Although such high levels of vaccination coverage are not reached in all countries, we opted to adopt this level in order to "eradicate" the disease (Anderson \& May, 1991). High levels of vaccination coverage are found in Hungary, Poland, the United States, and the Netherlands (Gangarosa et al., 1998). Such coverage may also be found locally within less vaccinated countries. The host-parasite-vaccine model 
is run for another 200 years, and the same epidemiological parameters are recorded for this period (after the initial transient is removed). To simulate the arrival of a new pertussis strain, we introduce a vaccine-resistant strain at this stage. This strain is clinically similar to the original one and should be diagnosed as pertussis. Previous infection with the original strain, however, does not protect against the new one. Thus, we assume that there is no cross-immunity.

\section{Results}

The results differ greatly, whether we assume lifelong or short-term immunity. Here, we present them separately.

\section{Assuming lifelong immunity}

Consider a non-vaccinated population, without previous exposure to pertussis. The introduction of a pathogen as transmissible as Bordetella pertussis should cause a major epidemic. As the disease settles down into an endemic pattern, however, infection becomes more concentrated among children. In our model, the average age of infected individuals is around 10 , with ca. $55 \%$ of cases among children under 10 (Figures $4 \mathrm{a}$ and $5 \mathrm{a}$ ). The reason for this pattern is that, after the first epidemic, most adults become immune to the disease. New outbreaks depend on building up a new pool of susceptibles. If we assume that recovered individuals do not lose their immunity, the only way to obtain new susceptibles is by birth (in real communities, immigration of susceptibles also contribute to the pool, although birth generally exceeds immigration). This age structure, predicted by our model as well as by others (Anderson \& May, 1991), agrees with notification data from the pre-vaccination era, when it is believed that nearly everyone got pertussis under the age of 15 (Hethcote, 1999).

Applying the vaccination program to our simulated community (with $95 \%$ coverage), we eradicate pertussis and prevent future outbreaks (Figure 4a). Even the periodical immigration of infectives is not able to trigger any secondary transmission. Anderson \& May (1991), using a mathematical model for pertussis, predict similar results. Such drastic reduction of pertussis incidence was noted in the United States and the Netherlands where, between the 1950s and 1980s, only occasional cases of pertussis were reported (CDC, 2000; de Melker et al., 1997).

\section{Figure 2}

Immunity wane follows equation (1) with $w=0.012$.

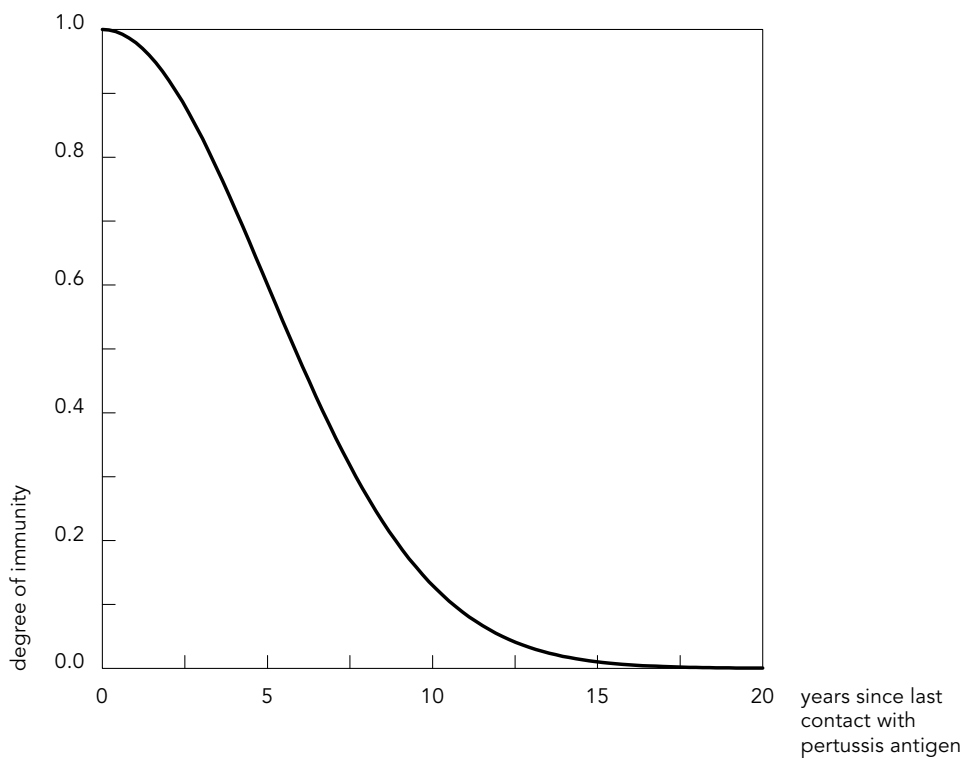

Table 1

Parameters for the simulation.

\begin{tabular}{ll}
\hline Parameters & Values \\
\hline $\begin{array}{l}\text { General parameters } \\
\text { World size }\end{array}$ & $100 \times 100$ \\
Population density & 2,500 \\
Host parameters & \\
Maximum age & 720 months $=60$ years \\
Death rate & All individuals die at 60 years \\
Birth rate & Balances death rate \\
Movement at each step & To a randomly chosen adjacent site \\
Parasite parameters & \\
Incubation time & \\
Period of infection & 0 \\
Contact distance & 2 months \\
Vaccine parameters & 3 sites \\
Coverage & \\
\hline
\end{tabular}


Figure 3

Simulation of the pertussis model ( $A$ ) assuming lifelong immunity; (B) assuming immunity wane. Each graph starts with a sample of the infected population dynamics in a non-vaccinated community (far left white section). The gray section shows the steady-state pertussis dynamics in a vaccinated community (for clarity, the transient phase was removed). The vaccine-resistant strain is introduced at time 1,000, and its dynamics is observed in the far right section of each graph.
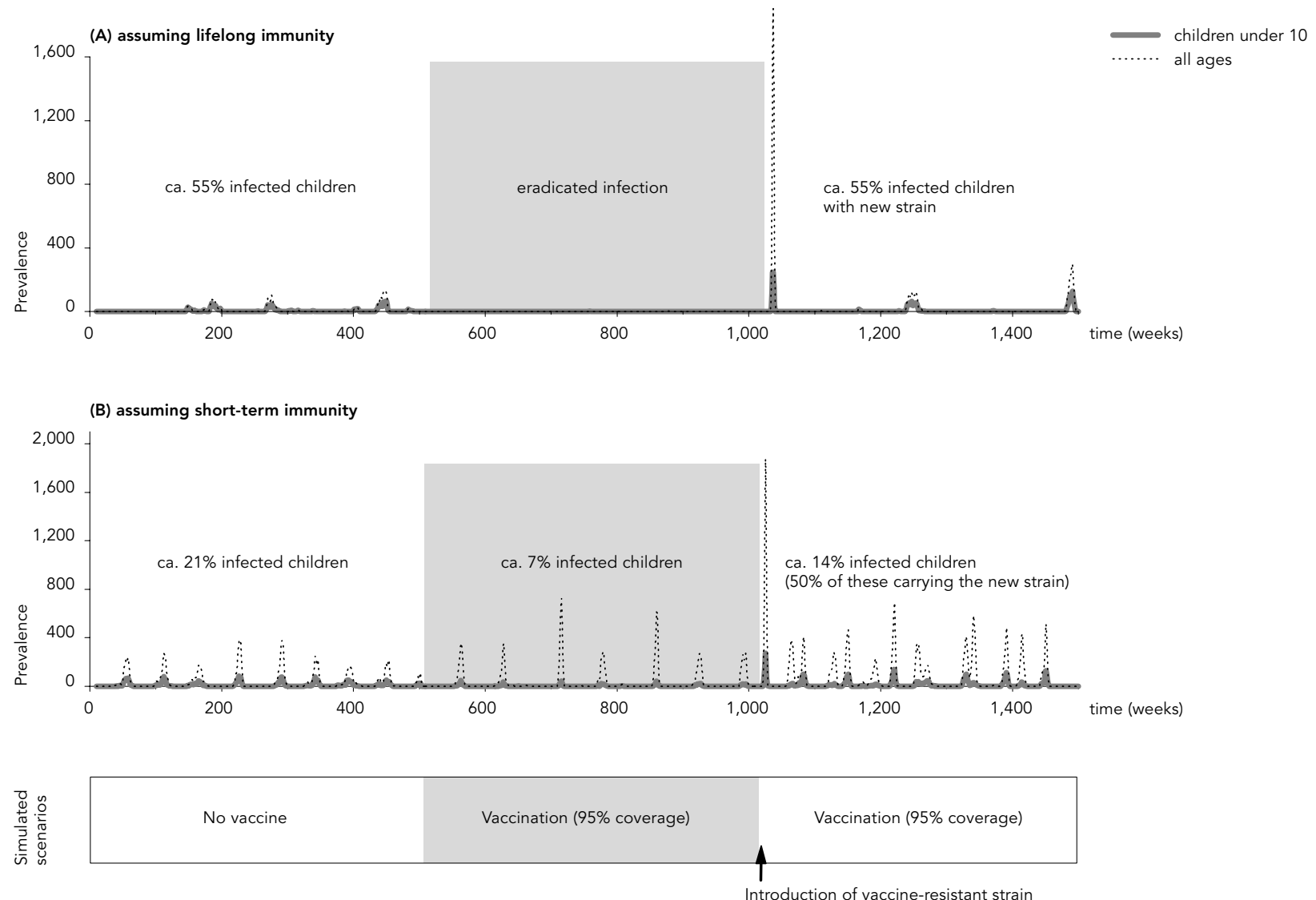

The introduction of a vaccine-resistant pertussis strain into the vaccinated community triggers a major epidemic (Figures $4 \mathrm{a}$ and $5 \mathrm{a}$ ). Since we assumed no cross-immunity between new and original strains, the new strain can be regarded as a completely different pertussis agent. Everyone is initially susceptible to the new strain, independently on previous contact with the original pertussis strain. As population immunity increases, the new infection displays endemic dynamics. Endemic equilibrium is similar to that found in the pre-vaccination era, with the same outbreak pattern and high incidence among children. Such similarity results from our assumption of complete equivalence between original and new strains in all epidemiological aspects, except antigen composition.

\section{Assuming immunity wane}

More in accordance with clinical observations, we simulate here a situation where immunity wanes with time. Consequently, individuals may catch pertussis more than once over the course of their lives. As expected, outbreaks are more frequent (compare Figures $3 a$ and $3 b$ ). The characteristic age structure, observed under the assumption of lifelong immunity, is replaced by a similar prevalence in all age groups. Short-term immunity reduces the relative prevalence of pertussis among children (from 
ca. $55 \%$ in the lifelong immunity scenario to ca. $21 \%$ in the short-term immunity scenario).

Applying the vaccination program to this community (95\% coverage) does not eradicate pertussis. Outbreaks of the same magnitude and frequency continue to occur as during the pre-vaccination period. However, we note a large reduction of infection among children. Shift of infection to older age groups happens because only children are protected by vaccination. As they grow up, they lose their immunity, becoming almost completely susceptible at age 12 .

The introduction of vaccine in the community does not change the magnitude and duration of the pertussis outbreaks. Thus, our results do not support the hypothesis of lack of natural boosting for the increasing prevalence of pertussis. However, as vaccination increases the average age at infection, lack of natural boosting could explain the increase of cases in adults.

The introduction of a vaccine-resistant pertussis strain into the vaccinated community triggers a major epidemic (Figure 3b). The dynamics are similar either assuming short-term or lifelong immunity. As the population becomes acquainted with the new strain, the new infection enters an endemic phase. Distribution of each strain within the host population is different. Children are mostly infected with the new strain (since they are vaccinated against the original one). Adolescents, on the other hand, are mostly infected with the original strain. Individuals in this age group have already lost their vaccine-acquired immunity to the original strain but are still resistant to the new strain (due to childhood infection). Adults are equally infected by both strains.

\section{Discussion}

Reemergence of pertussis in highly immunized countries has been reported by the United States and the Netherlands, raising concern about the effectiveness of the current pertussis control strategy. Many hypotheses have been proposed to explain increased pertussis notification. A modeling exercise can be very enlightening for questions like these. A model may help us to define testable hypotheses that will help us to distinguish between possible causes.

Pertussis is still considered a childhood disease by many clinicians. This view is based on the more visible symptoms of pertussis in children. Classical mathematical models of pertussis helped to corroborate this view (Anderson
\& May, 1991). By assuming lifelong immunity, these models predicted high prevalence of pertussis in children under 10 and an exponential decrease in prevalence towards older ages. Theoretical predictions based on the classical models were considered appropriate because they fit the surveillance data well (Anderson \& May, 1991).

Introduction of pertussis vaccine brought optimistic expectations to pertussis control. Since pertussis is human specific and no carriers exist, it did not seem impossible to eradicate pertussis via a wide-scale vaccination program. This view, still defended by some authors, was supported by the models, which predicted vaccination coverage of ca. $95 \%$ to eradicate pertussis (Anderson \& May, 1991). Actually, countries like the United States, the Netherlands, Hungary, Poland, and former East Germany that implemented high vaccination coverage rates noticed a sharp reduction in pertussis notification (Gangarosa et al., 1998).

One important assumption of classical pertussis models is lifelong immunity. However, this is not an adequate assumption. Pertussis cases have often been reported in vaccinated individuals or individuals with a past history of pertussis infection. Besides, more detailed epidemiological investigation has shown high prevalence of pertussis among adolescents and adults even in highly vaccinated communities. When the assumption of lifelong immunity is relaxed, a completely different picture emerges (Figure 4). While in the lifelong immunity model, most infection is concentrated in individuals under 10 years of age, in the short-term immunity model, prevalence is uniform throughout all age groups (except children under 5 years, which is still the most infected group). When vaccination is introduced in the shortterm immunity model, prevalence among children is greatly reduced but the older age groups remain unprotected. Pertussis is not eradicated, as predicted by the lifelong immunity model, but remains endemic in the population. If this is true, most pertussis cases in countries with low case-notification rates actually go unnoticed by the surveillance system. Field studies support this view. Comparing the age distribution of notified cases (Table 2) and the "true" prevalence (Table 3 ) in some communities, we observe a bias in the notification data towards children. More recently, development of agestructured mathematical models of pertussis that assumes immunity wane (de Melker et al., 2000; Hethcote, 1999) also indicates that prevalence in older age groups is greater than indicated by the surveillance system. 
Age distribution of infected individuals. Each graph corresponds to a different scenario, as presented in the six sections of Figure 3 (in the same relative positions).
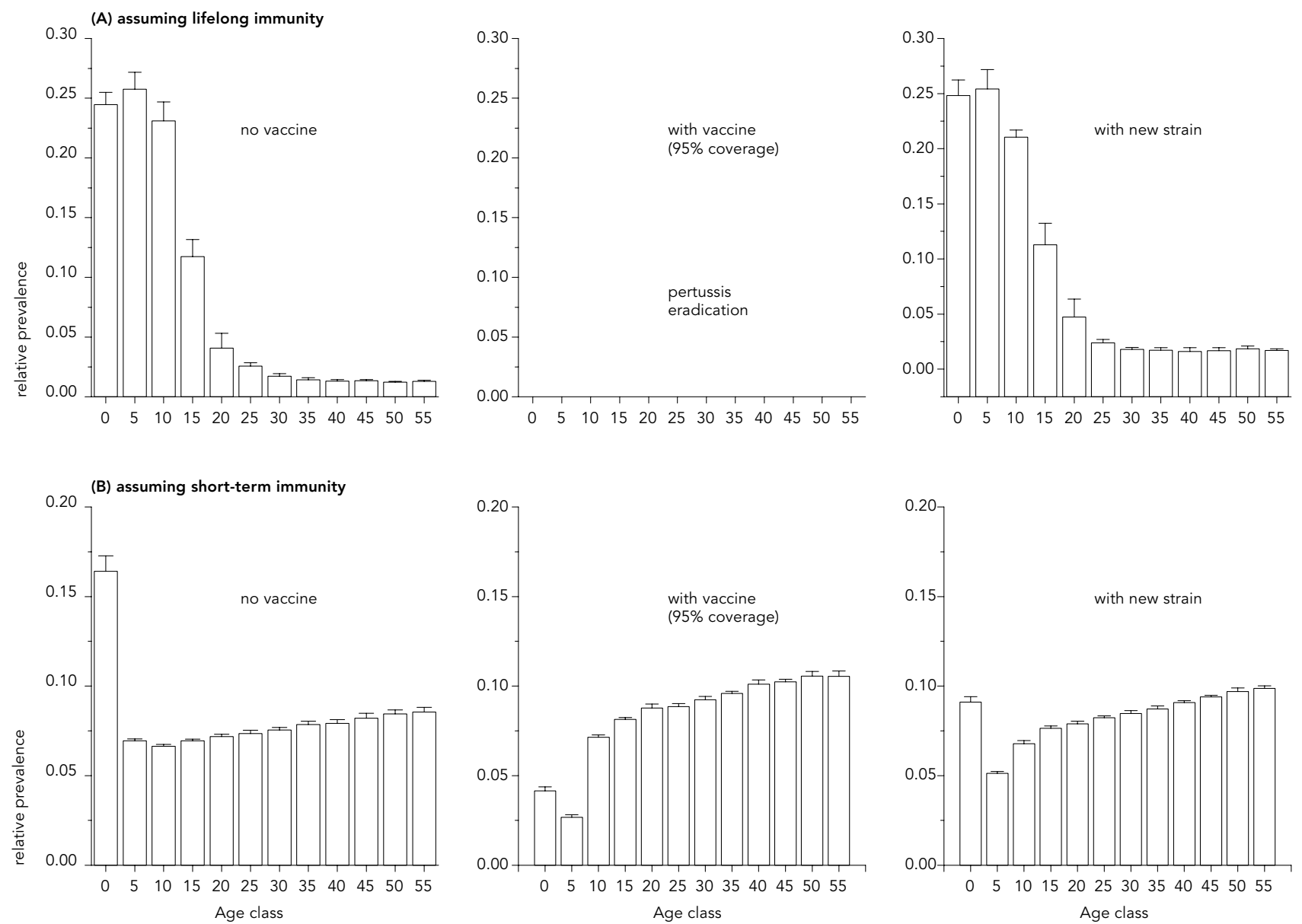

Table 2

Published epidemiological investigation of pertussis outbreaks.

\begin{tabular}{|c|c|c|c|c|c|c|}
\hline \multirow[t]{2}{*}{ Outbreak } & \multicolumn{6}{|c|}{ Age group } \\
\hline & $<1$ & $1-4$ & $5-9$ & $10-19$ & $>20$ years & Total cases \\
\hline Massachusetts, 1992a & 0.09 & $?$ & $?$ & 0.78 & $?$ & 225 \\
\hline Vermont, 1996b & 0.04 & 0.11 & 0.42 & 0.46 & 0.23 & 280 \\
\hline
\end{tabular}

a $96 \%$ and $\mathrm{b} 68 \%$ of cases had received at least 4 doses of vaccine. 
Notified cases of pertussis in the United States (CDC, 2000) and the Netherlands (de Melker, 1997).

\begin{tabular}{|c|c|c|c|c|c|c|}
\hline \multirow[t]{2}{*}{ Outbreak } & \multicolumn{6}{|c|}{ Age group } \\
\hline & $<1$ & $1-4$ & $5-9$ & $10-19$ & $>20$ years & Total cases \\
\hline United States, 1985-1998 & 0.40 & 0.19 & 0.12 & 0.17 & 0.12 & 63,000 \\
\hline Netherlands, 1989-1996 & 0.13 & 0.30 & 0.38 & 0.09 & 0.10 & 4,958 \\
\hline
\end{tabular}

A proposed hypothesis for the increasing pertussis notification rate in highly vaccinated countries is the lack of immunity-boosting infections. As contact with the pertussis agent becomes less frequent, adults should become more susceptible, and chances of acquiring the full-blown disease should increase. Our model suggests that lack of boosting infections is not enough to explain an increase in pertussis incidence in highly vaccinated populations, although it may explain the occurrence of more severe cases in older age groups.

A second hypothesis proposed for the increased pertussis notification is the emergence of a new B. pertussis strain. De Melker et al. (2000) shows that there was a change in the population structure of $B$. pertussis in the Nether-

\section{Acknowledgments}

This research was supported by Fundação de Amparo à Pesquisa do Estado do Rio de Janeiro (FAPERJ), Conselho Nacional de Desenvolvimento Científico e Tecnológico (CNPq), Financiadora de Estudos e Projetos (FINEP), and Programa de Apoio a Núcleos de Excelência (PRONEX). lands following the introduction of vaccination. However, his data cannot be extrapolated as evidence for the emergence of an antigenically distinct strain. Our model shows that the emergence of a vaccine-resistant strain could explain a sharp increase in pertussis incidence, like that observed in the Netherlands (de Melker et al., 2000). In the United States, however, the upward trend is less sharp (Hethcote, 1999) and does not suggest such drastic change in the underlying epidemiological dynamics. If de Melker's hypothesis is true, our simulations suggest some testable predictions about the distribution of $B$. pertussis strains in the population: a higher prevalence of vaccinated strains should be found in older hosts, while divergent strains should concentrate in younger individuals.

\section{References}

CDC (Centers for Disease Control and Prevention), 1993a. Pertussis Outbreaks - Massachusetts and Maryland, 1992. 1st August $2000<$ http://www.cdc. gov/mmwr/preview/mmwrhtml/00020038.htm>.

CDC (Centers for Disease Control and Prevention), 1993b. Resurgence of Pertussis - United States, 1993. 18 July 2000 <http://www.cdc.gov/mmwr/ preview/mmwrhtml/00023030.htm $>$.

CDC (Centers for Disease Control and Prevention), 1997. Pertussis Outbreak - Vermont, 1996. 25 July 2000 <http://www.cdc.gov/epo/mmwr/preview/ mmwrhtml/00049244.htm>.

CDC (Centers for Disease Control and Prevention), 2000. Pertussis. 18 July $2000<$ www.cdc.gov/nip/ publications/pink/pert.pdf $>$. 
DA SILVA, A. A. M.; GOMES, U. A.; TONIAL, S. R. \& DA SILVA, R. A., 1999. Vaccination coverage and some risk factors for non-vaccination in an urban area of Northeastern Brazil, 1994. Journal of Public Health, 33:147-156.

DE MELKER, H. E.; CONYN-VAN-SPAENDONCK, M. A. E.; RÜMKE, H. C.; VAN WIJNGAARDEN, J. K.; MOOI, F. R. \& SCHELLEKENS, J. F. P., 1997. Pertussis in The Netherlands: An outbreak despite immunization with whole-cell vaccine. Emerging Infectious Diseases, 3:175-178.

DE MELKER, H. E.; SCHELLEKENS, J. F. P.; NEPPELENBROEK, S. E.; MOOI, F. R.; RÜMKE, H. C. \& CONYN-VAN-SPAENDONCK, M. A. E., 2000. Reemergence of pertussis in the highly vaccinated population of The Netherlands: Observations on surveillance data. Emerging Infectious Diseases, 6:348-357.

EDWARDS, K. M.; DECKER, M. D. \& MORTIMER Jr. E. A., 1999. Pertussis vaccine. In: Vaccines (S. A. Plotkin \& W. A. Orenstein, ed.), pp. 293-344, Philadelphia: W. B. Saunders Company.

ENGEN, S., 1992. Sexual mixing models: A comparison of analogue deterministic and stochastic models. Mathematical Biosciences, 108:279-297.

FAUCI, A. S.; BRAUNWALD, E.; ISSELBACHER, K. J.; WILSON, J. D.; MARTIN, J. B.; KASPER, D. L.; HAUSER, S. L. \& LONGO, D. L., 1998. Harrison's Principles of Internal Medicine. New York: McGraw-Hill.

FERGUSON, N. M.; MAY, R. M. \& ANDERSON, R. M. 1997. Measles: Persistence and synchronicity in disease dynamics. In: Spatial Ecology: The Role of Space in Population Dynamics and Interspecific Interactions (D. Tilman \& P. Kareiva, ed.), pp. 137157, Princeton: Princeton University Press.

GANGAROSA, E. J.; GALAZKA, A. M.; WOLFE, C. R.; PHILLIPS, L. M.; GANGAROSA, R. E.; MILLER, E. \& CHEN, R. T., 1998. Impact of anti-vaccine movements on pertussis control: The untold story. Lancet, 351:356-361.

GOLDSTEIN, H., 1995. Multilevel Statistical Models. New York: Arnold.

HETHCOTE, H. W., 1997. An age-structured model for pertussis transmission. Mathematical Biosciences, 145:89-136.

HETHCOTE, H. W., 1999. Simulations of pertussis epidemiology in the United States: Effects of adult booster vaccinations. Mathematical Biosciences, 158:47-73.
HOLLAND, J. H., 1995. Hidden Order: How Adaptation Builds Complexity. New York: Helix Books.

HOLMES, E. E., 1997. Basic epidemiological concepts in a spatial context. In: Spatial Ecology: The Role of Space in Population Dynamics and Interspecific Interactions (D. Tilman \& P. Kareiva, ed.), pp. 111-136, Princeton: Princeton University Press.

LOMNICK, L., 1999. Individual-based models and the individual-based approach to population ecology. Ecological Modeling, 115:191-198.

MARCHANT, C. D.; LOUGHLIN, A. M.; LETT, S. M. TODD, C. W.; WETTERLOW, L. H.; BICCHIERI, R.; HIGHAM, S.; ETKIND, P.; SILVA, E. \& SIBER, G. R., 1994. Pertussis in Massachusetts, 1981-1991: Incidence, serological diagnosis, and vaccine effectiveness. Journal of Infectious Diseases, 169:12971305.

MILLER, E.; FLEMING, D. M.; ASHWORHT, L. A. E.; MABBETT, D. A.; VURDIEN, J. E. \& ELLIOTT, T. S J., 2000. Serological evidence of pertussis in patients presenting with cough in general practice in Birmingham. Communicable Disease and Public Health, 3:132-134.

PLOTKIN, S. A. \& ORENSTEIN, W. A., 1999. Vaccines. Philadelphia: W. B. Saunders Company.

RHODES, C. J. \& ANDERSON, R. M., 1996. A scaling analysis of measles epidemics in a small population. Philosophical Transactions of the Royal Society of London - Serie B - Biological Sciences, 351:1679-1688.

VAN BOVEN, M.; DE MELKER, H. E.; SCHELLEKENS, J. F. P. \& KRETZSCHMAR, M., 2000. Waning immunity and sub-clinical infection in an epidemic model: Implications for pertussis in The Netherlands. Mathematical Biosciences, 164:161-182.

VAN LOO, I. H. M.; VAN DER HEIDE, H. G. J.; NAGELKERKE, N. J. D.; VERHOEF, J. \& MOOI, F. R., 1999. Temporal trends in the population structure of Bordetella pertussis during 1949-1996 in a highly vaccinated population. Journal of Infectious Diseases, 179:915-923.

VERONESI, R. \& FOCACCIA, R., 1996. Tratado de Infectologia. São Paulo: Editora Atheneu.

WIEGAND, T., 1998. Population dynamics, disturbance, and pattern evolution: Identifying the fundamental scales of organization in a model ecosystem. American Naturalist, 152:321-337.

WRIGHT, S. W.; EDWARDS, K. M.; DECKER, M. D. \& ZELDIN, M. H., 1995. Pertussis infection in adults with persistent cough. JAMA, 273:1044-1046. 